\title{
Efficacy of ethanolic extract of propolis in maintaining postharvest quality of dragon fruit during storage
}

\begin{abstract}
Significant $(\mathrm{P} \leq 0.05)$ differences were observed in dragon fruit quality when treated with different concentrations of ethanolic extract of propolis (EEP) $(0.25,0.50,0.75$ and $1.0 \%)$ and stored at $20 \pm 2{ }^{\circ} \mathrm{C}$ and $80 \pm 5 \%$ relative humidity (RH) for 20 days. Fruit treated with $0.50 \%$ EEP showed the most promising results, while fruit treated with 0.75 and $1.0 \%$ EEP showed some phytotoxic effects even after 8 days of storage. The results of gas exchange analysis also proved the efficacy of $0.50 \%$ EEP concentration. Thus, it can be concluded from the present investigation that EEP at $0.50 \%$ concentration could be used to extend the storage life of dragon fruit without any negative effects on the quality.
\end{abstract}

Keyword: Antioxidant; Decay incidence; Dragon fruit; Propolis; Postharvest quality 